\title{
The BODE index predicted death in chronic obstructive pulmonary disease
}

Celli BR, Cote CG, Marin JM, et al. The body-mass index, airflow obstruction, dyspnea, and exercise capacity index in chronic obstructive pulmonary disease. N Engl J Med 2004;350:1005-12.

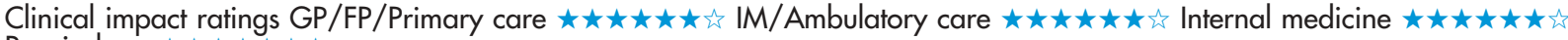

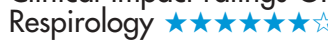

In patients with chronic obstructive pulmonary disease (COPD), how well does an index comprising the risk factors that reflect the respiratory, perceptive, and systemic aspects of the disease predict outcome?

METHODS

Design: 2 cohort studies, 1 for development and 1 for validation

(ii)

Setting: clinics in the US, Venezuela, and Spain.

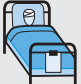

Patients: 832 patients (mean age 66 y) who had COPD with a wide range of severity, were in clinically stable condition, and were receiving appropriate therapy. Exclusion criteria: probability of death within 3 years from a cause other than COPD, asthma, inability to take the lung function and 6 minute walk tests, myocardial infarction within the previous 4 months, unstable angina, or congestive heart failure. 207 patients were recruited from 1995 to 1997 and formed the development cohort; 625 patients were recruited from 1997 to 2003 and formed the validation cohort.

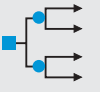

Description of prediction guide: the following variables were assessed for each patient in the development cohort: age, sex, pack years of smoking, FVC, FEV 1 , the best of two 6 minute walk tests done 30 minutes apart, degree of dyspnoea, body mass index (BMI), functional residual and inspiratory capacities, hematocrit and albumin levels, and degree of comorbid conditions. A logistic regression analysis determined the variables with the strongest association with 1 year mortality. 4 such variables (BMI [B], $\mathrm{FEV}_{1}$ as a percentage of the predicted value as an indication of airflow obstruction [O], score on the modified Medical Research Council [MMRC] dyspnoea scale [D], and the distance walked in 6 minutes as an indication of exercise capacity [E]) were included in the BODE index (0-10 points). Patients in the validation cohort were seen every 3-6 months for $\geqslant 2$ years or until death.

Outcomes: death from any cause and death from respiratory causes.

\section{MAIN RESULTS}

Higher BODE scores were associated with greater risk of death (table). In a model containing $\mathrm{FEV}_{1}$ or the BODE score as the independent variable, the $c$ statistic for the ability to predict risk of death was greater for the BODE index than for $\mathrm{FEV}_{1}(0.74 v 0.65)$.

\section{CONCLUSION}

In patients with chronic obstructive pulmonary disease, an index comprising measures of body mass index, degree of airflow obstruction and dyspnoea, and exercise capacity predicted all cause mortality and death from respiratory causes.

Abstract and commentary also appear in ACP Journal Club.

For correspondence: Dr B R Celli, St. Elizabeth's Medical Center, Tufts University School of Medicine, Boston, MA, USA. bcelli@copdnet.org Source of funding: no external funding.
BODE index for predicting death in chronic obstructive pulmonary disease*

\begin{tabular}{lll}
\hline Outcomes & Hazard ratio $(95 \% \mathrm{Cl}) \dagger$ & $\mathrm{p}$ Value \\
\hline $\begin{array}{l}\text { Death from all causes } \\
\text { Death from respiratory }\end{array}$ & $1.34(1.26$ to 1.42$)$ & $<0.001$ \\
causes & $1.62(1.48$ to 1.77$)$ & $<0.001$
\end{tabular}

*BODE = body mass index, airflow obstruction, dyspnoea, and exercise capacity.

tThe hazard ratio is for each 1 point increase in the BODE score.

\section{Commentary}

atients with COPD are often under treated, leading to much preventable morbidity, lost productivity, and economic cost. Identifying at risk patients could substantially improve outcomes.

The $F E V_{1}$ is the single best variable to stratify COPD severity. However, it does not accurately predict dyspnoea symptoms, exercise tolerance, and mortality. This is because COPD is a systemic disease, and airflow limitation alone does not capture all aspects of disease severity. FEV 1 may overestimate exercise tolerance because of dynamic hyperinflation or other non-ventilatory limitations. On the other hand, dyspnoea may even be absent because the patient has unconsciously narrowed their "envelope" of activity. Cigarette smoking also contributes to other causes of mortality in COPD, including cancer and cardiovascular disease, and is not reflected in the $\mathrm{FEV}_{1}$.

The study by Celli et al introduces the BODE index, which promises to be a very useful prognostic tool. The BODE index was constructed by broadening existing prognostic indicators and adding independent predictors of mortality to the $\mathrm{FEV}_{1}$. It is much more accurate and precise across the spectrum of COPD than any single prognostic factor. The mortality rate was double in the second cohort in this investigation, indicating that the index applied equally to more severe patients. It also predicted the $50 \%$ non-respiratory deaths.

New evidence-based guidelines for COPD emphasise early disease identification and stratification, using office spirometry. This facilitates implementation of exciting new long acting inhaled bronchodilators, pulmonary rehabilitation, oxygen treatment, and volume reduction surgery.

The BODE index adds another dimension to this effort by identifying at risk patients, who are most in need of our interventions. It goes beyond FEV 1 alone, using easily implemented office tools: the MMRC dyspnoea index, ${ }^{12} 6$ minute walk, and BMl as a measure of cachexia. ${ }^{3}$ It also encourages non-pulmonologists, who care for $80 \%$ of these patients, to obtain office spirometry and help identify those who are undiagnosed. Joseph A Golish, MD Cleveland Clinic Foundation Cleveland, Ohio, USA

1 Nishimura K, Izumi T, Tsukino M, et al. Dyspnea is a better predictor of 5year survival than airway obstruction in patients with COPD. Chest 2002;121:1434-40.

2 Mahler DA, Wells CK. Evaluation of clinical methods for rating dyspnea. Chest 1988:93:580-6.

3 Schols AM, Slangen J, Volovics L, et al. Weight loss is a reversible factor in the prognosis of chronic obstructive pulmonary disease. Am J Respir Crit Care Med 1998;157:1791-7. 